\title{
Os processos de escolarização na escola normal de Sapiranga/RS (1963-1966)
}

\section{Schooling processes at the normal school of Sapiranga/RS (1963-1966)}

José Edimar de Souza*

Resumo: O artigo busca compreender como se desenvolveu o processo de escolarização na escola Normal de Sapiranga, entre os anos de 1963-1966, primeiros anos de instalação do curso no município. A pesquisa analisa memórias orais e arquivadas, sob a perspectiva da História Cultural e valendose da metodologia da História Oral e análise documental. O corpus empírico origina-se de documentos produzidos pelas memórias e excertos de jornais. A memória é analisada como documento e contribui para a construção narrativa sobre o processo de implantação e primeiros tempos dessa instituição escolar. A sua contribuição não foi apenas para formar professores para a cidade, percebese que a sua constituição possibilitou a escolarização que modificou culturalmente esse lugar.

Palavras-chave: Memória. História Oral. Escola Normal.

Abstract: The article seeks to understand how the schooling process developed in Sapiranga Normal School, between 1963-1966, the first years of the course in the municipality. The research analyzes oral and archived memories, from the perspective of cultural history and using the methodology of oral history and documentary analysis. The empirical corpus originates from documents produced by the methodology of oral history and excerpts from newspapers. Memory is analyzed as a document and contributes to the narrative construction of the implantation process and early times of this school institution. The implantation of the institution contributed not only to train teachers for the city, it is possible to perceive the constitution of a possibility of schooling that culturally modified this place.

Keywords: Memory. Oral History. Normal School.

\footnotetext{
* Graduado em História e em Pedagogia. Mestre e Doutor em Educação, com estágio de pósdoutorado na UNISINOS. Professor e pesquisador do Programa de Pós-graduação em Educação da Universidade de Caxias do Sul - UCS. Vice-líder do Grupo de Pesquisa História da Educação, Imigração e Memória (GRUPHEIM).
} 


\section{Considerações iniciais}

É pela escrita da história que o historiador recompõe fatos edificados no espaço e no tempo, "[...] inventa o mundo, dentro de um horizonte de aproximações com a realidade. [...] processo este que envolve urdidura, montagem, seleção, recorte, exclusão, [...] cria o passado [...]”. (PESAVENTO, 2004, p. 54). Desse modo, com a seleção e organização cronológica e temporal, pretende-se conhecer, investigar e analisar os fatos do passado situados em um determinado espaço.

A renovação historiográfica do início do século passado possibilitou ao pesquisador ampliar o repertório de objetos de investigação no campo da História da Educação. Peixoto (1995, p. 10) acrescenta que "a nova história dilata a memória à medida que promove a dessacralização da memória de grandes homens". Esse aspecto alargou o conceito de documento e conferiu à história um novo status científico. A partir do movimento dos Annales (1929), "uma nova representação do tempo histórico" se desenvolveu teoricamente. A evolução dessa inovação, no método investigativo, possibilitou analisar acontecimentos considerando uma micronarrativa, narração da história de práticas, compartilhadas e configuradas no espaço e no tempo das memórias.

A "Nova História" problematiza e valoriza a micro-história, voltando-se à história da vida prática. A teoria desenvolvida pelos intelectuais desse movimento compila uma forma própria de análise do passado. Nessa nova visão, o historiador pesquisa e reflete sobre o uso de um método envolvendo ideias e questionamentos para serem analisados através de fontes diversas, como a memória, os documentos "ordinários", as imagens etc. (BURKE, 1992).

As memórias são portadoras de um sentido cultural vinculado a um espaço e tempo e encharcadas de uma experiência tátil, que Certeau (2011), nas suas mais elevadas reflexões, diz materializada nas relações cotidianas. Embora o aspecto do cotidiano não seja o foco deste trabalho, é possível conhecer, pela análise das representações, vestígios das práticas no cotidiano de uma instituição. Dessa forma, sob a perspectiva da História Cultural e valendo-se da metodologia da História Oral e análise documental, o objetivo deste trabalho foi 
compreender como se desenvolveu o processo de escolarização na escola Normal de Sapiranga, entre os anos de 1963-1966.

Sapiranga é um município do Vale dos Sinos ${ }^{1}$, situado no estado do Rio Grande do Sul e localizado na Região Metropolitana de Porto Alegre. Em 2015, a população representava cerca de 74.985 habitantes, distribuídos em uma área de 138,315 quilômetros quadrados (SAPIRANGA, 2015).

A História da Educação no município está associada à presença dos imigrantes alemães na região, a partir de 1826, sendo uma prática comum, em muitas localidades onde se estabeleceram esses imigrantes, a instalação de escolas junto das igrejas de Confissão Luterana. Conforme Gevehr (2015), em Sapiranga, a escola da comunidade era dirigida pelo pastor João Jorge Klein, que ministrava as aulas em sua residência. Essa escola originou a mais antiga instituição e que ainda se encontra em funcionamento: o atual Instituto Sinodal Duque de Caxias, fundado no ano de 1850.

Na década de 1930, a presença da escola pública começa a se efetivar na localidade. Em 10 de fevereiro de 1934, foi criado o grupo escolar Sapiranga, denominado hoje Instituto Estadual Coronel Genuíno Sampaio (SAPIRANGA, 2015). Além disso, a história de Sapiranga está imbricada à história de São Leopoldo, considerando que só em 28 de fevereiro de 1955 é que a emancipação acontece e possibilita os primeiros tempos de organização de uma estrutura administrativa independente.

Em relação à implantação dos cursos secundários, a extensão do ensino primário ocorreu em 1955, com a criação do curso ginasial (Decreto $\mathrm{n}^{0} 6.749$, de 22 de novembro de 1955, criou o Ginásio. Com a Portaria ${ }^{0}$ 512, de 12 de março de 1956, foi autorizado o funcionamento, porém as aulas iniciaram em 22 de abril de 1956), e na sequência surgiu o curso técnico e profissionalizante: Comercial e Normal. O ensino secundário no início da década de 1960, na região do Vale dos Sinos, era realizado em algumas instituições privadas, especialmente, no Colégio Santa Catarina ou no São Jacó, em Novo Hamburgo. Nesse sentido, um dos projetos que endossou as políticas de emancipação dos municípios, como Campo Bom, Sapiranga, entre outros, foi a proposta de

\footnotetext{
${ }^{1}$ Região próxima a Porto Alegre, capital do Estado do Rio Grande do Sul. Recebeu esse nome em função do Rio dos Sinos, principal recurso hídrico que corta os municípios que compreendem esse vale, por exemplo, Estância Velha, São Leopoldo, Parobé, Sapiranga, Novo Hamburgo, Campo Bom, entre outros.
} 
ampliação dos níveis de ensino, antes apenas atendidos pela escolarização primária.

\section{Memórias e documentos: fontes para compor uma história da escola normal}

A escrita da história como prática representa uma possibilidade para ler, traduzir e interpretar vestígios do passado (LOPES, FARIA FILHO; VEIGA, 2000). A História da Educação é aqui entendida como um "território" da investigação histórica, que se articula em sua pluralidade em diversos níveis e que agrega diferentes saberes. Nesse sentido, a pesquisa se constitui em um "trabalho histórico orientado no sentido abrangente, ou seja, capaz de ler os processos histórico-educativos" (CAMBI, 1999, p. 33). Desse modo, os processos de escolarização representam as práticas sociais estabelecidas pelos sujeitos em um determinado espaço e tempo.

Entende-se que os processos de escolarização evidenciam os modos de organização, de desdobramento de ações de distintos grupos sociais, de uma relação com a cultura, bem como nos permitem compreender uma forma escolar, em que os ritos e as práticas se materializam e se ordenam.

A escolarização corresponde aos processos políticos estabelecidos para que um projeto comum de educação se institucionalize. Desse modo, aspectos como estatística escolar, componentes curriculares, o ensino da leitura, da escrita e das relações entre métodos e a história das instituições indicam referências sociais para se conhecer os meios pelos quais se buscou estruturar uma pretensa rede ou redes de ensino.

O modo dinâmico e as implicações com os processos de escolarização se desenvolvem no cotidiano das instituições e adquire pelo viés da História Cultural resultados que valorizam os sentidos construídos e compartilhados pelos sujeitos envolvidos em uma situação escolar associada ao seu processo formativo. Nesse sentido, Faria Filho (2011, p. 253) acrescenta que, "[...] ao longo do processo de escolarização, é necessário considerar os deslocamentos dos lugares ocupados pelos sujeitos no interior das culturas escolares".

O tempo escolar, um dos aspectos da Cultura Escolar, resulta de uma construção histórica, na acepção de Viñao Frago (1995), que o considera uma 
invenção humana, e que conforma noções que os seres humanos fazem do seu sentido e de seus efeitos. Essa Cultura Escolar se constitui pela ação dos atores sociais - professores, pais, alunos - e a relação direta e indireta com a comunidade de pertencimento. O espaço escolar, como espaço de síntese de práticas culturais, compreende um "[...] conjunto de aspectos institucionalizados - incluy prácticas y conductas, modos de vida, hábitos y ritos [...]”, (VINÃO FRAGO, 1995, p. 68), englobados em suas características organizativas, modalidades e níveis de instrução.

As memórias analisadas neste trabalho abrangem diferentes naturezas documentais. $\mathrm{O}$ conjunto da empiria investigada decorre de consulta a acervos do Arquivo do Instituto de Educação Estadual Sapiranga (AIEES) e do Arquivo do Museu Municipal Adolfo Evaldo Lindenmeyer (AMMAEL) e de entrevista oral realizada com a ex-aluna, professora aposentada Renilda Adi Gerhardt, bem como com uma funcionária da escola, Erica Santos.

A memória se constrói de lembrança e também de esquecimentos. É nesse sentido que há, na lembrança, rememorações e vazios. Ou seja, o processo de lembrar implica escolhas entre os fatos do passado que, por algum motivo, são privilegiados por quem recorda. Quando evocado, o passado surge percebido por uma lente do presente. Nesse caso, tanto o passado quanto o presente sofrem interferência (SOUZA, 2016). É pela narração do tempo que os sujeitos "arrancam" do passado o que ainda sobrou da tradição, do costume ancestral.

Halbwachs (2006) considera que os entrecruzamentos e as recorrências de memórias são produtoras de uma possível verdade e que se fortalecem na medida em que as lembranças se multiplicam pelos membros do grupo. Revel (2009) acrescenta que a percepção do tempo social, proposta por Halbwachs, pode ser apreendida como um "novelo de relações de interdependências" entre os diferentes fenômenos inscritos no tempo.

A dimensão espaço e tempo assume, nesta pesquisa, uma proporção dinâmica do tempo social, um tempo que se compõe pelas relações estabelecidas por um dado grupo social aqui investigado. O tempo social é aquele construído pelos sujeitos da pesquisa ao revisitarem suas memórias. É 
ainda o tempo construído pelas representações sociais e pelos documentos selecionados, recortados e organizados para este estudo.

Para Halbwachs (2006), a passagem do tempo em espaço percebido, a partir das memórias, possibilita conhecer e compreender como as características históricas, políticas e sociais, que identificam um grupo específico, foram construídas; pelas interações e/ou desenvolvimento de experiências que os grupos vinculam às suas histórias.

Desse modo, carregamos conosco nossas reflexões individuais, que são originadas noutros grupos, reais ou imaginários. A realidade construída é resultado das memórias de grupos e instituições que estão nos contextos nos quais fazemos parte, portanto, no presente, quando da experiência carregamos conosco as memórias das tramas que constituem nossas referências passadas ou atuais.

Os documentos são produtos de diversas práticas de escrita. São seus detalhes que auxiliam a compreender o contexto em que emergiu tal produto social. Além disso, nenhum texto mantém uma relação transparente com a realidade que apreende, como argumenta Chartier (2002), nem mesmo os quadros estatísticos que podem representar serem menos subjetivos do que a escrita narrativa, ou ignorar os jogos de sentidos presentes na heurística de sua produção.

Para Cellard (2014), a história social modificou a abordagem no uso de fontes documentais. Assim, para que o historiador consiga compor a narrativa construída sobre um determinado objeto, vale-se de práticas que envolvem organização, desconstrução e reconstrução de dados edificados nos documentos.

O que torna uma fonte documental relevante em uma investigação é a seleção, o modo de organização e as questões elaboradas na construção da sua análise. São as perguntas que o pesquisador define e as lentes que utiliza para analisar teórico e epistemologicamente que possibilitam recompor cenários vividos a partir de vestígios e dos instrumentos escolhidos pelo investigador. Para Certeau (2011), a partir da problemática construída pelo investigador, no presente, produzem-se novos sentidos ao conjunto e aos fatos históricos narrados. "Ao recriar aquilo que está morto, ele torna vivo e mutável o saber 
produzido [...] Nesse processo, precisa-se levar em conta os desvios [...] e as descontinuidades" (MORAES; GAMBETA, 2011, p. 168).

As memórias trazidas pela voz dos sujeitos, que viveram em um determinado tempo e espaço, são documento construído e produzido pelo historiador. Assim, Grazziotin e Almeida (2012) afirmam que esse procedimento agrega o risco e as implicações de encontrar uma verdade, que se constrói em função da posição ocupada pelo historiador, na instituição histórica de sua época.

Vidal (2007) acrescenta que a natureza do documento em educação é escriturária, pois é no espaço escolar que se encontram os resultados das relações pedagógicas e burocráticas, por meio de diários de classes, históricos escolares, exames, boletins, cadernos de alunos, ou seja, registros realizados por professores, alunos e pela gestão da escola, que caracterizam o funcionamento e as práticas da instituição escolar.

A partir da análise documental, buscou-se identificar o modo como, em diferentes lugares e momentos, uma determinada realidade social é construída. Nesse sentido, cotejar diferentes documentos, como as memórias arquivadas e orais, possibilitou ampliar a construção e compreensão dos sentidos sobre as práticas desenvolvidas para instituir a escola normal nesse lugar.

\section{A Escola Normal de Sapiranga nas narrativas escritas e orais ${ }^{2}$}

A institucionalização de um sistema de formação de professores no Brasil, na segunda metade do século XIX, foi um processo moroso e que, apenas na década de 1930, apresenta práticas mais consistentes para atender à demanda social dos professores de primeiras letras. Em relação à história da Escola Normal no Rio Grande do Sul, pesquisadores como Tambara (2008) têm se dedicado ao estudo do seu processo de constituição. Schneider (1993) argumenta que, desde a sua constituição, em 1860, até o fim da primeira república no Brasil, diferentes regulamentos orientaram a estrutura e

\footnotetext{
2 Este estudo configura-se como um desdobramento do projeto de investigação financiado pelo Conselho Nacional de Desenvolvimento Científico - CNPq-Brasil. Edital Universal 01/2016: "Modos de Organizar a Escola Primária no RS (1889-1950): histórias, memórias e práticas educativas". Processo número: 405151/2016-0.
} 
organização do ensino de formação3 de professores no nosso Estado. A Escola Normal foi criada em 5 de abril de 1869 e reorganizada em 7 de março de 1877 e em 4 de fevereiro de 1881. Em 14 de março de 1901, foi substituída pelo Colégio Distrital da Capital4.

Tambara (2008) destaca que, em contrapartida à falta de uma política mais determinante para a formação de professores, surgem os cursos vinculados às confissões religiosas, tanto da Igreja Católica quanto dos sínodos luteranos. Além disso, o Estado firmava convênios com instituições "reconhecidas e idôneas" para suprir o número insuficiente da oferta de vagas em escolas complementares. Nesse período, uma nova configuração começa a se constituir, e uma das instituições que buscou dar continuidade ao curso primário, funcionando, de modo geral, como um curso geral básico de preparação para Escola Normal foi o Curso Primário Complementar, como argumenta Tanuri (2000, p. 70):

Nestas condições, introduzia-se em nosso sistema de ensino uma bifurcação nos estudos gerais imediatamente após a escola primária: o curso complementar, espécie de primário superior, propedêutico à escola normal, de duração, conteúdo e regime de ensino interiores ao secundário, e este último, de caráter elitizante, objeto de procura dos que se destinavam ao ensino superior. A criação do curso complementar estabelecia um elo de ligação entre a escola primária e a normal e o ingresso na última passava a exigir maiores requisitos de formação.

Para Amaral (2008), as características regionais da oferta dessa modalidade de ensino objetivaram a preparação de futuros professores que

3 Para Guimarães (2016), o exercício da docência existe desde a Antiguidade e antecede a existência de cursos preparatórios de professores. A percepção da necessidade de formar professores existe desde o século XVI, nos países da Europa, mas a organização de escolas públicas estatais para preparação desses profissionais ocorreu com a criação dos cursos normais, a partir do século XIX, no contexto da modernidade. Destacam-se como escolas normais europeias aquelas fundadas na Prússia (Alemanha) e na França, sendo este último país o que influenciou a implantação dessa instituição em países latino-americanos. Estima-se que as escolas normais se constituíram do modelo instituído na França a partir de 1833, pelo Ministro da Instrução Pública François Guizot, auxiliado por Victor Cousin. A estrutura exigia frequência ao referido curso para exercício do magistério, bem como fixou um salário para os docentes.

4 O Colégio Distrital de Porto Alegre foi substituído pela Escola Complementar, em função do Decreto $\mathrm{n}^{\circ}$ 907, de 16 de maio de 1906, sendo que em ambos os modelos o ensino deveria ser orientado pelo método intuitivo (TAMBARA, 2008). No Estado do RS, a partir do Decreto $\mathrm{n}^{\mathrm{o}}$ 1.479, de 26 de maio de 1909, a formação de professores primários era realizada pela Escola Complementar da capital. Somente com o Decreto $\mathrm{n}^{0} 3.898$, de 4 de outubro de 1927, é expedido novo regulamento para instrução pública, referindo-se à formação de professores primários, possibilitando também a formação em escolas complementares equiparadas. Contudo, o Decreto $\mathrm{n}^{\mathrm{0}}$ 4.277, de 13 de março de 1929, regulamentou o ensino normal e complementar, alterando a denominação de Escola Complementar novamente para Escola Normal (BERGOZZA, 2010). 
desejassem atuar no ensino primário. Werle (1997) acrescenta que, praticamente, esse curso buscava aperfeiçoar os conhecimentos básicos com uma formação complementar para o desenvolvimento do magistério e representou um grande empreendimento do Estado nas diferentes localidades em que fora instalada ao longo do primeiro quartel do século XX.

Em 1943, havia no Estado sete escolas oficiais e dezoito equiparadas. No Vale dos Sinos, identificam-se duas escolas equiparadas, a saber: Escola Santa Catarina, em Novo Hamburgo, e Escola São José, em São Leopoldo. De fato, a partir de 1946, com a elaboração e aprovação da Lei Orgânica do Ensino Normal, a formação de professores para o ensino primário passa por uma nova configuração. E as escolas complementares oficiais passavam, a partir dessa data, a denominar-se Escolas Normais (TAMBARA, 2008). Além disso, a Lei Orgânica de 1946 pretendia garantir que a formação do pessoal docente, administradores escolares para as escolas primárias e a propagação de conhecimentos técnicos relativos à infância fossem ensinados nas escolas normais. E, para exercer magistério gaúcho, portanto, os estudantes deveriam passar por um dos três tipos de instituições previstas: Curso Normal Regional, Escola Normal ou Instituto de Educação.

As modalidades de ofertas eram distintas e os títulos expedidos em cada umas dessas formas de ensino diferenciavam-se: no curso Normal Regional, era possível cursar o primeiro ciclo, de quatro séries anuais, após o curso primário complementar, com as disciplinas obrigatórias do curso ginasial; a conclusão do curso certificava Regente de Ensino Primário. Na Escola Normal, os cursos eram de segundo ciclo, e o ciclo ginasial secundário, em três séries anuais, após o ciclo ginasial ou de curso de regente ou curso profissional básico, sendo estes dois últimos suplementados por exames de disciplinas do curso ginasial que não tivessem sido estudados, como argumenta Tambara (2008). No Instituto de Educação, as possibilidades eram o curso de Escola Normal e a especialização do magistério e de habilitação para os administradores escolares do grau primário, ofertados em duas séries anuais. Nestes dois últimos casos, a titulação era de Professor Primário de $1^{\circ}$ e $2^{\circ}$ graus.

Uma ação política do Rio Grande do Sul no contexto da formação de professores foi a criação, em 1943, do Centro de Pesquisas e Orientação 
Educacionais, o CPOE/RS, que, conforme Quadros (2006), ocupou papel fundamental na formação e disseminação científica e administrativa de serviço de instrução primária. Além de realização de cursos, seminários, conferências, o centro era responsável pela publicação de materiais pedagógicos que pretendiam atualizar docentes com novas técnicas e conhecimento educacional.

A década de 1950 é marcada pelo aspecto do desenvolvimentismo e forte presença do incentivo à urbanização e à industrialização. Para Quadros (2001), no governo de Leonel Brizola e de Ildo Meneghetti, houve um incentivo educacional nunca antes percebido no Estado. Esse aspecto procurava elevar índices de resultado do aproveitamento educacional, valorizar e qualificar professores; melhorias que repercutiram ainda na melhor qualidade de vida, de promoção da saúde, da diminuição da desigualdade social e da violência, do acesso à cidadania e do fortalecimento democrático.

Em 1955, o governo do Estado aprova um novo regulamento para o Ensino Normal no Rio Grande do Sul, através do Decreto n. 6004, de 26 de janeiro de 1955. Como a lei era muito flexível em relação à regulamentação do sistema de ensino, muitas Escolas Normais não incorporaram suas diretrizes imediatamente. Uma das principais características de alteração em relação à legislação anterior se referia à passagem da unidade letiva de anual para semestral (TAMBARA, 2008). Nesse documento, destaca-se a consolidação do sistema de dois ciclos e reformula o ensino normal rural, que passou a ser ofertado pela Escola Normal Regional.

A década de 1960, estabelecida como marco principal deste trabalho, foi um período de intensas transformações no Brasil e no mundo. No cenário mundial, o momento era de reformulação de paradigmas e intensa movimentação em torno dessas mudanças. Apesar disso, no Brasil, essa década foi marcada pela implantação do regime ditatorial, deflagrado em março de 1964. Em alguns momentos das falas das entrevistadas, é possível ver referência a práticas estabelecidas nesse período - embora, muitas vezes, tais colocações sejam naturalizadas pelas depoentes, de modo que identificam determinada questão como referente ao regime após colocações do entrevistador.

Como já argumentado em outro estudo, no âmbito educacional, o regime militar procurou ajuda externa e buscou articular a política educacional com 
metas e objetivos traçados no plano econômico (SANFELICE, 2011). Através do acordo entre o Ministério da Educação (MEC) e a United States Agency for International Development (USAID), foi promovida uma reforma no ensino brasileiro: "O governo se declarava firmemente empenhado em abrir caminho para o desenvolvimento nacional, não poupando esforços e recursos no aprimoramento e expansão do ensino em todos os seus graus" (SANFELICE, 2011, p. 329).

Para Magalhães (1998), o estudo da história de uma instituição educativa representa possibilidade de compreender as relações que existem entre o contexto investigado, um modo de recortar o tempo e analisar as relações organizacionais, pedagógicas e humanas que evidenciam elementos da cultura de um lugar. Nesse sentido, valendo-se das memórias arquivadas e orais, entendo que o trabalho da memória se encontra encharcado de subjetividade de quem conta, rememora, identifica e elabora uma narrativa para compor com esses indícios aspectos desses primeiros tempos da instituição investigada.

Para ampliar a compreensão sobre o contexto investigado, valeu-se na composição da análise de outros documentos além da entrevista oral realizada com uma aluna da primeira turma do curso Normal. Dessa forma, documentos diversos, como relatórios, ofícios, entre outros, foram acessados no arquivo do AIEES e no AMMAEL, bem como excertos dos jornais O Ferrabraz e Folha de Sapiranga.

A professora Renilda Adi Gerhardt assinou Termo de Consentimento Livre e Esclarecido e optou pela sua identificação neste estudo. Ela nasceu em 1940, é natural de Campo Bom e sua trajetória profissional se desenvolveu nesse município. É importante destacar que este texto não tem a pretensão de construir a trajetória profissional dessas professoras, mas valer-se de memórias associadas ao momento em que Renilda foi aluna da primeira turma do Curso Normal, entre 1963-1966. A primeira turma formou-se no dia 13 de agosto de 1966. Das vinte e três normalistas apenas dezesseis ainda vivem. Atualmente, ela e as demais colegas da primeira turma do curso Normal passaram a se reunir periodicamente. Em 2016, quando se festejou os 50 anos de formatura, elas realizaram uma visita ao atual curso normal do Instituto de Educação Estadual Sapiranga. O encontro realizado em torno da galeria dos quadros de formados 
pela instituição foi um momento para "refletir sobre o magistério atual, falar da educação... do que é mesmo ser professora”, relembra professora Renilda, na entrevista realizada em 2017.

A história da criação de um Curso Normal público, em Sapiranga, foi uma demanda que envolveu ações de diferentes grupos da comunidade escolar, além da ação política da administração municipal. Nesse sentido, entendemos tais práticas como táticas no sentido de sensibilizar o governo do Estado em prol desse Curso no munícipio. Como argumenta Certeau (2011), pela arte da tática o sujeito busca atribuir novo sentido às práticas em que está envolvido. Nesse sentido, o processo da autorização e criação do curso envolveu as alunas que cursavam o Ginásio Estadual de Sapiranga, os pais, autoridades políticas, religiosas e representantes do setor empresarial.

Em 1927, com a emancipação de Novo Hamburgo, outros distritos que constituíam São Leopoldo iniciaram a realização de censo, de votação popular e composição de grupos que trabalhassem pela emancipação. Sapiranga contou com iniciativas emancipacionistas desde a década de 1940. E, com a emancipação, em 1955, a ampliação dos níveis de ensino figuraram dentre as propostas do primeiro governo municipal. Um exemplo desse desdobramento foi a implantação do curso Ginasial, que, a partir de 1956, também era oferecido no período noturno.

As narrativas que evidenciam o jogo de poder que envolveu os primeiros tempos da Escola Normal estão imbricadas a ações que desdobram as iniciativas que decorrem do projeto da institucionalização do Grupo Escolar, a partir de 1934. Percebe-se que, além de petições, atividades em prol da qualificação, melhoria e desenvolvimento dos espaços em que funcionou essa instituição, contaram com uma mobilização e integração em torno da escola, ou da possibilidade que a continuidade dos estudos poderia contribuir ao progresso da embrionária cidade, emancipada em 1955.

É possível identificar que, em 1962, após aprovação do curso Normal, o governo Estadual recuou na sua posição em relação à oferta dos dois tipos de cursos. Em matéria publicada pelo jornal O Ferrabraz, em 23 de fevereiro de 1963, há referência à mobilização das alunas para que tanto o $1^{\circ}$ quanto $02^{0}$ ciclo fossem oferecidos em Sapiranga: 


\begin{abstract}
Alunas do $1^{\mathrm{O}}$ ciclo do curso da futura Escola Normal Regional a instalar-se em Sapiranga estariam organizando-se em comissão, com a finalidade de apelar as autoridades constituídas e que está afeto êste grau de ensino, para que à 4 de março seja realmente iniciado o referido curso. Pois conforme tivemos conhecimento, foram aprovados nos exames de habilitação 35 candidatos; já possuindo todo o material de secretaria, pare do material didático e organização da biblioteca já se encontra a cargo da Diretora Profa. Adelina Antonelli dos Santos. Inclusive podemos afirmar que, a animação dos alunos é tamanha, que, já promoveram a organização de uma quermesse para a qual angariaram uma grande coleção de prêmios diversos, estão ainda realizando uma rifa em benefício da Escola da qual tendo vendido quase todos os números, prova está com isso que, a iniciativa foi muito bem recebida pela população de Sapiranga.

Dita comissão, consta-nos que compõe-se das seguintes senhoras alunas do curso: Dora Klyppel, Ivone Peters, Recy Costa e Cely Sefrin, além de outras. Fizemos questão de destacar que, existem grande parte de alunas que residem fora da sede, considerando ainda que, grande parte já são professôras e que estão lecionando a cargo do munícipio.

Seria deveras lamentável sê, agora que tudo está devidamente preparado com o devido carinho para o início do curso, que por certo muito benefício trará a nossa mocidade estudantil fosse pelos poderes público, eliminado o curso do $1^{\circ}$ ciclo da referida escola, desesperando e inclusive tirando-lhes o seu entusiasmo aos estudos.

Nós também serramos fileiras ao lado desta comissão, solicitando ao Govêrno do Estado, a concretização da escola com o início do curso do $1^{0}$ cíclo da Escola Normal de Sapiranga, curso êsse que consideramos indispensável ao início da grande e tão útil carreira de professores, ainda no ano em curso e para o próximo mês de março. Expressamos aqui também o nosso apelo aos poderes constituídos do estado, para que sejam atendidas em suas aspirações à comissão das alunas da Escóla Normal Regional de Sapiranga, a instalar-se brevemente (O FERRABRAZ, 1963, capa)5.
\end{abstract}

Em 1962, o prédio que abrigava o grupo escolar e o ginásio estadual de Sapiranga foi ampliado, e implantou-se o Colégio Estadual de Sapiranga. Nesse sentido, passou a funcionar o Curso Ginasial, Científico e Colegial ou o Clássico. Com a ampliação do prédio, a instituição passou a abrigar outros cursos, como o Curso Normal Regional de $1^{\circ}$ Ciclo, autorizado pelo decreto $\mathrm{n}^{0} 13.927$, de 26 de julho de 1959, e o de $2^{\circ}$ Ciclo, decreto $n^{0} 14.363$, de 19 de novembro de 1962.

Em 5 de março de 1963, a professora Adelina Antonelli dos Santos, diretora da Escola Normal, comunica que a criação de duas escolas havia sido aprovada pela superintendência do Ensino Normal. A professora Maria Luiza Roth realizou in loco vistoria técnica pelo município para acompanhar e avaliar a estrutura do prédio do Grupo Escolar Coronel Genuíno Sampaio. Para Gevehr (2007), o nome da escola é uma homenagem ao soldado imperial que morreu

5 Tratando-se de uma pesquisa histórica, optou-se pela manutenção da redação referente ao contexto original de produção da fonte. 
após ferir-se em um embate do episódio dos Mucker, em 1874. A Fotografia 1 permite visualizar que o prédio onde fez funcionar o Grupo Escolar, a Escola Normal e também Escola Comercial possuía a estrutura de uma residência familiar. As pequenas adaptações presentes na edificação, como a parte alta acima do telhado semelhante a uma escada, pretendia aproximar-se da visão "monumental” dos "Templos da República”, como argumenta Souza (2009).

Fotografia 1 - Grupo Escolar de Sapiranga - década de 1950.

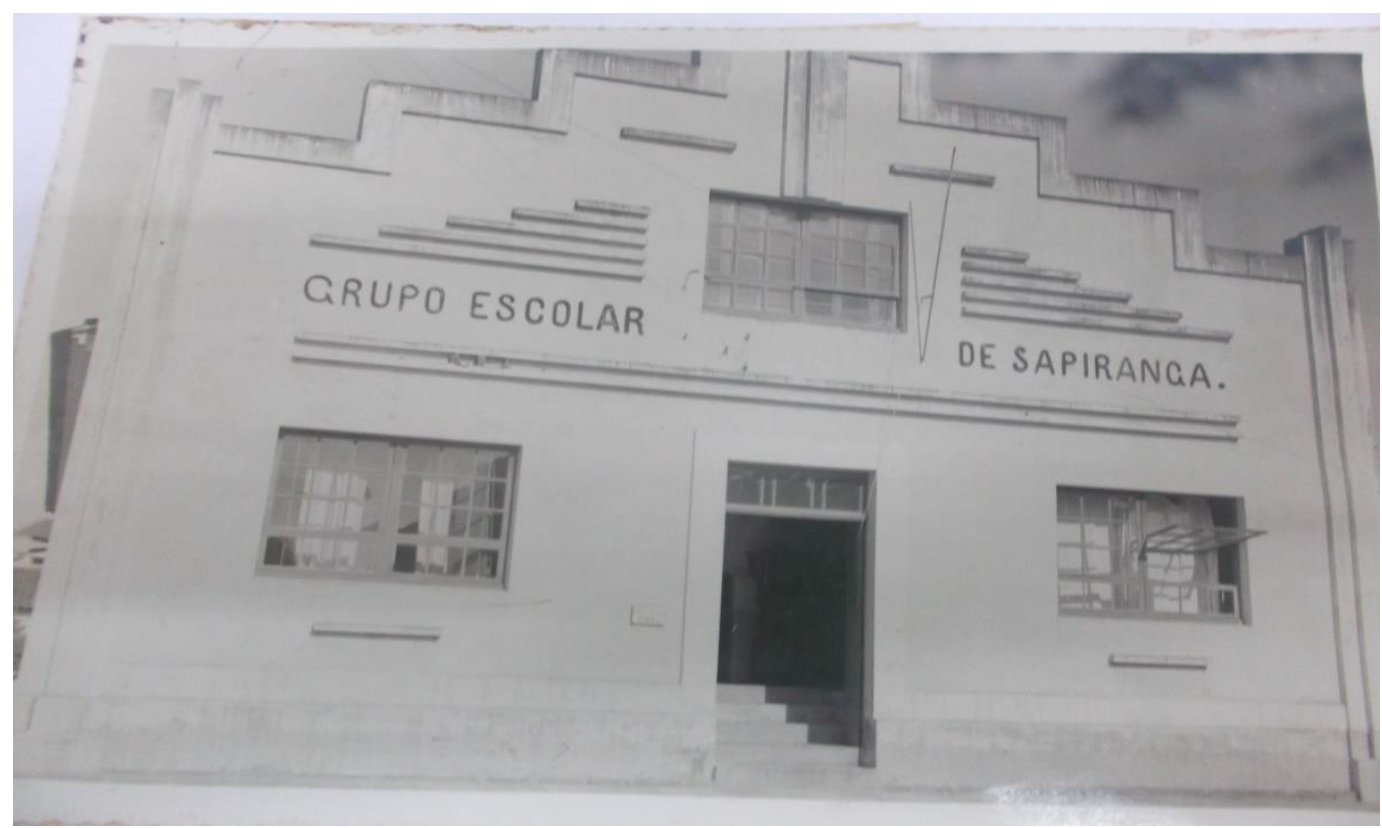

Fonte: Acervo do AIEES.

Os primeiros tempos da Escola Normal de Sapiranga, utilizando o prédio do Grupo Escolar, foram de adaptações ${ }^{6}$ de espaços e também de materiais que serviriam para as aulas. Em entrevista com Érica7, que fora uma das primeiras funcionárias da instituição, era auxiliar de disciplina, ela rememora que, para

\footnotetext{
${ }^{6}$ A escola funcionava no prédio do Grupo Escolar Coronel Genuíno Sampaio, onde dispunha de duas salas. Havia a compra de um terreno pela prefeitura para a construção de um prédio próprio, ou um pavilhão. Não havia instalação para Educação Física. Para essa atividade, utilizava-se o salão do Colégio Sagrado Coração de Jesus, gentilmente cedido pelo vigário do município.

7 Começou a trabalhar no Grupo Escolar em março de 1950. Foi aluna do grupo no final da década de 1930. O professor Hugo lecionava Alemão e Português.
} 
dar conta do número de alunos que aumentava com a ampliação da oferta dos diferentes níveis de ensino, era preciso muita disciplina: “[...] mas eu nunca tive dificuldade com isso, eram umas crianças muito boas, os alunos sempre me respeitavam [...] ajudando, fazia um pouco de tudo [...]" (SANTOS, 2015, entrevista). Ela narra que teve um período que veio um professor que participou da Segunda Guerra Mundial, ele contribuiu para que os alunos aprendessem a fazer "fila reta", era o professor Hugo Werner Grossi.

Em outra matéria assinada pela administração municipal, o prefeito enfatiza ofício e memorial encaminhado ao governador do Estado, Senhor Leonel de Moura Brizola. A análise da narrativa presente no jornal Folha de Sapiranga, de 16 de abril de 1962, endossa que a reivindicação pela instalação de uma escola de formação de professores em Sapiranga abrangeria alunas da região do Vale dos Sinos. Outro aspecto que reforça o argumento do prefeito Helmuth Alfredo Graebin é de que a escola normal contribuiria para a concretização do projeto da gestão Brizola (1959-1963) "Nenhuma criança sem escola no Rio Grande do Sul", que pretendia escolarizar "totalmente" o Rio Grande do Sul, como indica Quadros (2001).

Oportuno memorial dirigido ao governador do Estado, com assinatura das autoridades executivas, legislativas e de elementos representativos de tôdas as classes de nossa comunidade. Movimento dos mais expressivos está se registrando em nosso meio, pela instalação de uma escola normal estadual nesta cidade, o que, convenhamos, já era tempo de se concretizar. Neste sentido, ao que estamos informados, o prefeito municipal, senhor Helmuth Graebin, fez chegar às mãos do governador do Estado um requerimento, acompanhado de extensa exposição de motivos e firmado por tôdas as autoridades executivas, legislativas e outros destacados representantes da nossa Comunidade. Inclusive por inúmeras alunas do Ginásio Estadual.

Trata-se de um movimento dos mais simpáticos, que visa a acautelar os interêsses da nossa população estudantil, principalmente feminina, pela ausência absoluta de um estabelecimento gratuito dêsse gênero em tôda a chamada região do Vale do Rio dos Sinos. Concluíndo o curso ginasial, vemos - com pezar - nossas jovens estudantes iniciarem a "via-sacra" das estradas, em busca dos estabelecimentos particulares de outras cidades, numa peregrinação penosa e dispensiosa de sua vocação para o magistério. [...] só há, atualmente, duas outras soluções: abandonar os estudos ou declinar a vocação, ingressando em carreira diversa, mesmo que o mercado de trabalho local não lhes acene com grandes esperanças.

Daí a necessidade desse apelo às autoridades estaduais, que encamparem com entusiasmo, divulgando, na íntegra, o texto do memorial enviado ao diretor chefe do Executivo Rio Grandense e que enquadra perfeitamente no seu esquema de escolarização total do Estado. (FOLHA DE SAPIRANGA, 1962, capa). 
A questão da possibilidade da continuação dos estudos é aspecto que rememora alguns dos sujeitos entrevistados na ocasião de outras pesquisas que venho desenvolvendo nessa região. A instalação dos grupos escolares foi algo significativo do ponto de vista da qualificação para o trabalho. É importante destacar que, nessa região, no início do século XX, a indústria calçadista e dos derivados do couro encontravam-se em prospecção. Contudo, a partir da segunda metade deste século, o curso primário já não era mais suficiente. A implantação do curso ginasial, científico e técnico comercial, a partir de 1955, sinaliza que a diversificação profissional é um cenário que se desenha como perspectiva para essa comunidade. Além disso, os exames de admissão cumpriam um papel determinante na escolha do futuro de muitos alunos.

O ingresso no curso ginasial ocorria diante da aprovação nos exames de admissão, uma forma de reprimir a população que teria acesso aos graus mais elevados de escolarização. A obrigatoriedade legal da aplicação dos Exames de Admissão ao Ginásio ocorreu de 1931 a 1971. Souza (2008) argumenta que era uma forma de privilegiar o "seleto grupo social" que se valia da educação pública secundária para realizar a "reconversão do capital econômico em capital cultural". Esse aspecto pode ser entendido como uma forma elaborada pelo Estado para solucionar o problema da falta de oferta de vagas que as legislações a partir de 1946 indicavam com a obrigatoriedade do ensino secundário.

Em relação aos impactos psicológicos causados pelos exames, o desconforto dos estudantes com a presença de inspetores e fiscais de ensino, além do controle do Estado, fazia com que muitos reprovassem. Outro aspecto relevante para compreender essa questão é que esse instrumento de avaliação ainda denunciava a precariedade do atendimento das escolas públicas, especialmente as instaladas no meio rural, considerando que a padronização de tais provas de seleção não representava as particularidades de cada região e realidade de ensino.

Para o Curso Normal, no jornal Folha de Sapiranga, de 15 de setembro de 1962, o edital de inscrição para o curso preparatório indicava como as inscrições deveriam acontecer. Era necessário apresentar certidão de nascimento e comprovar ter mais de 13 anos até a data de início da admissão; certidão de conclusão do curso primário ou atestado de escolaridade em caso de o candidato 
ainda não ter completado o curso primário; atestado de boa conduta ${ }^{8}$ fornecido pela direção do Grupo Escolar ou por dois professores da localidade; uma fotografia e requerimento à direção da escola solicitando inscrição. Além disso, os candidatos deveriam apresentar, no dia do exame de admissão, o atestado de saúde física e mental.

O processo de ampliação da oferta dos níveis de ensino no município favoreceu a comparação de que Sapiranga estava se transformando em uma "autêntica colmêia de estudantes" (FOLHA DE SAPIRANGA, 1962, p. 4). Sobre o período de ampliação das escolas em Sapiranga, Renilda, egressa da primeira turma do curso Normal, rememora:

[...] surgiu esta escola do Magistério de Sapiranga. Aí eu não sei porque eu não fiz, ou eu não fiquei sabendo. Porque isso foi divulgado no ginásio, nas escolas ginasiais, principalmente de Sapiranga. Porque as meninas daqui de Campo Bom que terminavam o primário iam fazer o ginásio em Sapiranga porque não tinha, aqui ainda, depois é que foi criado o ginásio em Campo Bom" (GERHARDT, 2015, entrevista).

Os exames de admissão ao Curso Normal aconteceram em dezembro de 1962, porém, de acordo com a professora Renilda Gerhardt (2015), no início do ano de 1963, houve um processo seletivo especial para preencher as vagas remanescentes, no mês de fevereiro. Como ela recorda, foi durante uma reunião de início de ano, conduzida pela supervisora Norma Zerwes, da $2^{\mathrm{a}}$. Delegacia de Ensino do Estado, que ela ficou sabendo desse período especial.

O Ensino Normal de $1^{\circ}$ Ciclo no Estado, correspondente ao nível ginasial, era conhecido em Sapiranga como Curso Normal Rural, e destinava-se, geralmente, a aqueles professores que já exerciam docência leiga, em muitos casos, em escolas multisseriadas. Nesse sentido, o candidato realizava exame de admissão, necessitava apresentar o certificado de conclusão do Ensino Primário e a habilitação no Exame de Admissão e, após quatro anos de estudo, recebia o

\footnotetext{
8 A ideia disseminada nesse contexto associava o comportamento da futura professora ao respeito aos homens, obediência, resignação, ao comportamento ordeiro, passivo e vocacionado. Fischer (2005) acrescenta que se esperava que a professora fosse referência aos alunos, na formação de futuros "soldados da pátria". Cunha (2009) indica que as alunas deveriam ser dóceis e amáveis, bem como temerosas a Deus, pois esse exemplo garantiria o futuro seguro do progresso do país. É evidente que nesta comunidade as famílias se conheciam e a figura paterna ainda exercia um papel significativo, na década de 1960, na influência das escolhas profissionais das suas filhas. Outro aspecto rememorado pelas entrevistadas é que as próprias lideranças públicas e autoridades, e isso incluía os professores da escola normal, faziam deferência para indicar: "[...] fulana é da família tal [...]". A origem étnica e/ou sobrenome também era um indicativo para futuras oportunidades.
} 
diploma de Regente de Ensino Primário. A Lei Orgânica do Ensino Normal, Decreto-Lei n. 8.350, de 1946, normatizou o ensino normal nacionalmente, instituindo três tipos de estabelecimentos: o instituto de educação, a escola normal e os cursos normais regionais. Os Cursos Normais Regionais eram considerados o Primeiro Ciclo do Ensino Normal e Secundário, com quatro séries anuais, e destinava-se à formação de regentes de ensino primário.

Os relatórios da primeira turma do Curso de Regente de Ensino Primário - $1^{0}$ Ciclo da Escola Normal de grau ginasial e colegial iniciou em 15 de abril de 1963 e sua organização era semestral. A direção do corpo docente, como se identifica no Quadro 1, estava sob os cuidados da professora Adelina Antonelli dos Santos:

Quadro 1- Corpo docente curso regente de ensino primário (1963)

\begin{tabular}{|l|l|l|}
\hline Professor & Ciclo & Disciplina(s) \\
\hline Celina Cecília Reich Sabater & $\mathbf{1}^{\mathbf{0}}$ Ciclo & Música \\
\hline Helena Maria Pinto Barcellos & $\mathbf{1}^{\mathbf{0}}$ Ciclo & Ciências Naturais \\
\hline Jacira Maria Menezes da Silva & $\mathbf{1}^{\mathbf{0}}$ Ciclo & Desenho \\
\hline Dr. João Stéfano de Césaro & $\mathbf{1}^{\mathbf{0}}$ Ciclo & Português \\
\hline Lourdes C. Panatieri Lerotic & $\mathbf{1}^{\mathbf{0}}$ Ciclo & Atividades Econômicas \\
\hline $\begin{array}{l}\text { Lourdes Conceição Panatieri } \\
\text { Lerotic }\end{array}$ & $\mathbf{1}^{\mathbf{0}}$ Ciclo & Valores Morais \\
\hline Maria do Carmo Coutinho Travi & $\mathbf{1}^{\mathbf{0}}$ Ciclo & Educação Física \\
\hline Reinaldo Ignácio Adams & $\mathbf{1}^{\mathbf{0}}$ Ciclo & Matemática \\
\hline Teresinha de Jesus Valls Azzalini & $\mathbf{1}^{\mathbf{0}}$ Ciclo & Geografia e História \\
\hline
\end{tabular}

Fonte: Elaborado pelo autor a partir dos relatórios do curso (1963-1966).

Renilda Gerhardt era professora leiga e iniciou como docente em uma "Brizoleta", em 1959, na Escola Estadual La Salle, de Novo Hamburgo, no bairro Canudos, atuando como contratada pelo convênio entre prefeituras municipais e o Serviço de Expansão Descentralizada do Ensino Primário (SEDEP).

E, em 1963, no contexto da política de expansão do ensino, a supervisora das escolas estaduais, professora Norma Zerwes, havia notificado a professora Renilda sobre a prioridade que as novas contratadas, com formação do Curso Normal, teriam diante daquelas professoras que apenas tinham o curso ginasial, ou eram regentes. A prioridade de atuação em escolas situadas no espaço urbano era concedida às professoras com formação mais elevada. Já as professoras "leigas" eram deslocadas para o espaço rural, bem como para localidades mais distantes nos municípios que compreendiam a região de abrangência da $2^{\text {a }}$ Delegacia de Ensino. 
De acordo com Renilda, a professora Norma lembrou que ainda havia possibilidade de realizar o vestibular para ingressar no Curso Normal. Caso ela se interessasse, talvez, fosse possível que ela permanecesse na mesma escola. Sobre esse processo, ela rememora:

[...] a Dona Norma me deu uma chance. E eu fui a Sapiranga, eu fui atrás. Acho que era terça ou quarta-feira. Vamos dizer assim, eu peguei uma semana para arrumar a documentação toda e fazer a prova. [...] Acho que tinha umas dez, nessa segunda chamada, que eles chamavam. Passamos só duas. Eu tirei o primeiro lugar e a outra tirou o segundo. Eu não achei difícil, porque eu trabalhava com $5^{\circ}$ ano no Lassale. Então, aquele conteúdo do [exame] Admissão, aquele "problemão", desse tamanho. História do Brasil, conhecimentos gerais, era pouquinho mais História do Brasil, redação. E fui fazer o Magistério [suspiro]. E aí consegui uma escola lá em Sapiranga. As nossas aulas eram de tarde. Eu fui lá para escola, lá no bairro São Luís, lá perto do Rio. E à tarde eu ia pra Escola no Magistério (GERHARDT, 2015, entrevista).

Renilda enfatiza que a primeira turma do curso Normal era constituída de vinte e três alunas, pois não havia alunos. "Naquela época, homem não era professor. Era só mulher!” (GERHARDT, 2015, entrevista). Conforme constam nos relatórios semestrais do curso, disponíveis no acervo do AMMAEL, inscreveram-se para o exame de admissão 78 candidatas, mas compareceram 51 e apenas 34 efetivaram a matrícula. Contudo, a matrícula geral é de 35 alunas, considerando a existência de uma aluna que já havia cursado um ano na Escola Regional de São Francisco de Paula. Do município de Campo Bom, eram quatro alunas: ela, Liane Bauer, Ondina Schumann, hoje Burzlack, e Carla Wenzel, hoje Becker. Renilda ainda destaca o fato de estar no segundo grau, convivendo com outras colegas, de diferentes lugares, com distintas experiências. Segundo ela, foi algo determinante para crescer e aprender muito.

Em relação ao currículo do curso, não existiam muitas atividades práticas. $\mathrm{O}$ destaque da formação para o exercício do magistério dedicava uma significativa parte das aulas para o domínio do conhecimento teórico, de Ensino Religioso, Sociologia, Filosofia, Didática, Matemática, Literatura e Língua Portuguesa, como se identifica no Quadro 2, abaixo, que indica também o nome dos docentes da instituição: 
Revista Brasileira de História \& Ciências Sociais - RBHCS

Vol. $12 N^{\circ}$ 24, Julho - Dezembro de 2020

Quadro 2- Corpo docente curso de professora primária (1963)

\begin{tabular}{|l|l|l|}
\hline Professor & Ciclo & Disciplina(s) \\
\hline Celina Cecília Reich Sabater & $2^{\mathbf{O}}$ Ciclo & Música \\
\hline Helena Maria Pinto Barcellos & $2^{\mathbf{O}}$ Ciclo & Ciências Naturais \\
\hline Icis Leci Machado Medeiros & $\mathbf{2}^{\mathbf{O}}$ Ciclo & Filosofia \\
\hline Icis Leci Machado Medeiros & $\mathbf{2}^{\mathbf{O}}$ Ciclo & Psicologia \\
\hline Jacira Maria Menezes da Silva & $\mathbf{2}^{\mathbf{O}}$ Ciclo & Desenho \\
\hline Dr. João Stéfano de Césaro & $\mathbf{2}^{\mathbf{O}}$ Ciclo & Português \\
\hline $\begin{array}{l}\text { Lourdes Conceição Panatieri } \\
\text { Lerotic }\end{array}$ & $\mathbf{2}^{\mathbf{O}}$ Ciclo & Valores Morais \\
\hline Maria do Carmo Coutinho Travi & $\mathbf{2}^{\mathbf{O}}$ Ciclo & Educação Física \\
\hline Reinaldo Ignácio Adams & $\mathbf{2}^{\mathbf{O}}$ Ciclo & Matemática \\
\hline Teresinha de Jesus Valls Azzalini & $\mathbf{2}^{\mathbf{O}}$ Ciclo & Ciências Sociais \\
\hline
\end{tabular}

Fonte: Elaborado pelo autor a partir dos relatórios do curso (1963-1966).

Souza (2008) e Ramos (2005) enfatizam que esse currículo era enciclopédico, rígido e que supervalorizava o mérito individual. Desse modo, o ambiente escolar era de disciplina, respeito e "medo", os alunos eram "preparados" para responderem de forma clara, objetiva. A experiência prática auxiliava, pois havia um clima de "austeridade" no ambiente escolar, no qual os alunos eram solicitados a responder adequadamente às lições, arguições orais e escritas.

Sinalizo que os relatórios semestrais entregues pelos professores do curso ainda podem ser melhor explorados, pois constituem de matéria-prima rica para compreender o cotidiano da cultura escolar produzida nesses primeiros tempos de implantação do curso normal. E, mesmo que o saudosismo da memória de egressas e das representações da comunidade local seja repleto de adjetivos para esse fato, há de se observar que as dificuldades iniciais se assemelham aos outros espaços em que o braço do Estado procurou cumprir minimamente a sua função de promover educação pública ao maior número possível de interessados. Contudo, cito exemplo do discurso presente no relatório do professor de português, João Stéfano de Césaro, que, em 1963, sinalizava "[...] o baixo nível cultural e social dos alunos, bem como o problema com a falta de materiais didáticos para cumprir o programa do semestre [...]". Já em 1964 e 1965, demonstra uma conformidade em evidenciar mudança na sua postura e na forma de dizer aquilo que era necessário ser dito: “[...] modificação de atitude do professor, podemos esperar aperfeiçoamento do ensino primário, médio e secundário em geral, mas a faísca inicial que deve 
produzir a chama terá que nascer na sala de aula [...]”, ou seja, a responsabilidade da mudança dependeria apenas do professor.

A situação do novo contexto político se percebe a partir dos relatórios de 1965, em que se sugere uma nova narrativa, coerente com o governo. No relatório do professor João Césaro, como referido anteriormente, vale-se de textos da professora Dalilla Sperb9, demonstrando a tensão diante de um novo cenário social, cultural e educacional. Esse depoimento não pode ser considerado isoladamente, pois a visão nacionalista, doutrinária e progressista evidencia-se no relato de outros professores ${ }^{10}$. Entretanto, a escola normal ultrapassa esse período e projeta-se como uma instituição que irá se consolidar ao longo da década de 1960. Os relatórios também indicam a procura de jovens e experientes estudantes até a década de 1970.

\section{Considerações finais}

Em Sapiranga, a mobilização para a implantação do curso Ginasial e, posteriormente, os cursos de Segundo Grau, como o Curso Normal, se caracteriza pela iniciativa de diferentes setores da comunidade. Importante ressaltar que o discurso da campanha emancipacionista sinalizava "inconformidade" com o fato de "não haver ainda no município" uma instituição dessa natureza.

A efetiva expansão para todo o território nacional das escolas destinadas a formar professores para o ensino primário ocorreu a partir da década de 1950, época em que as escolas normais se consolidaram como uma instituição essencialmente feminina, isso acontece em Sapiranga a partir de 1962. As escolas eram dotadas de escolas-modelo anexas, destinadas à prática

\footnotetext{
9 Foi umas das primeiras professoras do Vale dos Sinos a cursar doutorado em educação nos Estados Unidos, pela Universidade de Colúmbia. Além de atuar como supervisora e delegada de ensino, escreveu obras expressivas sobre administração escolar, além de atuar em diferentes órgãos municipais e estaduais, como diretoria da instrução pública e o CPOE (SOUZA, 2015). Autora de obras como Problemas gerais de currículo (1966) e Administração e Supervisão na Escola Primária (1963), ambas publicadas pela editora Globo.

${ }^{10}$ Como exemplo, podemos citar o relatório da professora Lourdes Conceição Panatieri Lerotic, que sinaliza o ensino da moral cristã. Além disso, a referida professora substitui a regente da disciplina de História, e o título do projeto desenvolvido pela professora Lerotic foi "O homem e o progresso". Em 1964, no segundo semestre, identifica-se que o projeto da Escola Normal passou a ter um lema, assumido pelos alunos, assim identificado: "Ordem e progresso: Ordem em tudo e progresso nos estudos".
} 
pedagógica, e foram responsáveis pela profissionalização do magistério primário no Brasil.

É importante salientar que este texto apresenta um pequeno recorte temporal da história da instituição, priorizando aspectos da primeira turma formada pelo Curso Normal. Nesse sentido, cabe destacar que, em 1969, o grupo escolar é transformado em escola primária de aplicação da Escola Normal "Coronel Genuíno Sampaio", para as alunas normalistas e que atuariam em escolas da região funcionando até 1972. Até 1975, a instituição funcionou no prédio situado na Rua Carlos Biehl, tendo abrigado tanto o Grupo Escolar como, posteriormente, o Ginásio e os Cursos Técnicos de Comércio e Escola Normal.

A implantação da instituição contribuiu não apenas para formar professores para a cidade, percebe-se a constituição de uma possibilidade de escolarização que modificou culturalmente esse lugar. A presença da Escola Normal contribuiu para que Sapiranga se constituísse como um lugar de referência na formação de professores. Esse aspecto se reverbera até os dias atuais, sobretudo, para alunos que buscam uma formação para o exercício da docência de forma pública, gratuita e de qualidade. Além disso, houve ampliação do processo de formação de um grupo significativo de jovens da região de abrangência dessa escola, além de contribuir para instituir novas práticas e a inclusão da figura da aluna normalista e da professora com mais frequência nos espaços de sociabilidade do município.

\section{Referências}

AMARAL, Giana Lange do. A escola complementar de Pelotas: 1929-1943. In: TAMBARA, Elomar; CORSETTI, Berenice (Org.). Instituições Formadoras de Professores no Rio Grande do Sul. Pelotas: UFPel, 2008. p. 193-214.

BERGOZZA, Roseli Maria. Escola Complementar de Caxias: histórias da primeira instituição pública para formação de professores na cidade de Caxias do Sul (1930-1961). 2010. 174 p. Dissertação (Mestrado em Educação) Universidade de Caxias do Sul, Programa de Pós-graduação em Educação, Caxias do Sul, 2010.

BURKE, Peter (Org.). A escrita da história: novas perspectivas. São Paulo: Edunesp, 1992.

CAMBI, Franco. História da Pedagogia. Tradução de Álvaro Lorencini. São Paulo: Editora UNESP, 1999. 
CELLARD, André. A análise documental. In: POUPART, Jean et al. A pesquisa qualitativa. Enfoques epistemológicos e metodológicos. Trad. Ana Cristina Arantes Nasser. 4 ${ }^{\text {a }}$ Ed. Petrópolis, RJ: Vozes, 2014, p. 295-316.

CERTEAU, Michel de. A escrita da história. Tradução de Maria de Lourdes Menezes, Revisão técnica de Arno Vogel. 3. ed. Rio de Janeiro: Forense Universitária, 2011.

CHARTIER, Roger. À beira da falésia: a história entre incertezas e inquietude. Trad. De Patrícia Chittoni Ramos. Porto Alegre: Ed. da UFRGS, 2002.

CUNHA, Maria Tereza Santos. Saberes impressos escritas da civilidade e impressos educacionais. (Década de 1930 a 1960). In: YAZBECK, Carolina; ROCHA, Marlos Bessa Mendes da. (Orgs.). Cultura e História da Educação: intelectuais, legislação, cultura escolar e imprensa, Juiz de Fora: Editora UFJF, 2009, p. 233-251.

FARIA FILHO, Luciano Mendes de. Fazer História da Educação com E. P. Thompson: trajetórias de um aprendizado. In: FARIA FILHO, Luciano Mendes de. Pensadores sociais e História da Educação. Belo Horizonte: Autêntica, 2011, p. 265-292.

FISCHER, Beatriz Terezinha Daudt. Professoras: histórias e discursos de um passado presente. Pelotas: Seiva, 2005.

GEVEHR, Daniel Luciano. Deutsche Evangelische Vereinsschule Sapyranga e Genuíno Sampaio: lugares de memória e espaços de formação entre a germanidade e a brasilidade no sul do Brasil. Revista História UNICAP. Pernambuco, PE, v. 2, $\mathrm{n}^{\mathrm{0}}$ 4, jul./dez. 2015, p.12-26.

GEVEHR, Daniel Luciano. Pelos Caminhos de Jacobina: memórias e sentimentos (res)significados. Tese de Doutorado (Doutorado em História). Programa de Pós-graduação em História, Centro de Ciências Humanas, Universidade do Vale do Rio dos Sinos - UNISINOS, São Leopoldo, 2007.

GUIMARÃES, Rosângela Maria Castro. O ensino de História da Educação na Escola Normal. Entre o prescrito e a realidade escolar (Uberlândia, Minas Gerais, 1928-1970). Uberlândia: EDUFUS, 2016.

GRAZZIOTIN, Luciane Sgarbi Santos; ALMEIDA, Dóris Bittencourt. Romagem do tempo e recantos da memória. Reflexões metodológicas sobre História Oral. São Leopoldo: Oikos, 2012.

HALBWACHS, Maurice. A memória coletiva. São Paulo: Centauro, 2006.

LOPES, Eliane Marta Teixeira.; FARIA FILHO, Luciano Mendes.; VEIGA, Cynthia Greive. 500 anos de educação no Brasil. $4^{\text {a }}$. Ed. Belo Horizonte: autêntica, 2000.

MAGALHÃES, Justino. Um Apontamento metodológico sobre a História das Instituições Educativas. In: SOUZA, C., CATANI, D. (Org.). Práticas educativas, culturas escolares, profissão docente. II Congresso Lusobrasileiro de História da Educação. São Paulo, Escrituras, 1998. p. 51-69.

MORAES, José Geraldo Vinci de; GAMBETA, Wilson. Michel de Certeau: pensador das diferenças. In: REGO, Teresa Cristina et al. (Org.). Memória, 
história e escolarização. Petropolis, RJ: Vozes, São Paulo, SP: Revista Educação; Editora Segmento, 2011. p. 157-182. (Coleção Pedagogia Contemporânea).

PEIXOTO, Anamaria Casasanta. A escola ontem: inventário urgente e necessário. In: MINISTÉRIO DA EDUCAÇÃO E DO DESPORTO -MEC. Instituto Nacional de Estudos e Pesquisas Educacionais. INEP. Seminário História da Educação Brasileira: a ótica dos pesquisadores. Belo Horizonte, 17 a 20 de maio de 1994. Série Documental, n, 6, abr. 1995, p. 09-11.

QUADROS, Claudemir de. Brizoletas: a ação do governo de Leonel Brizola na educação pública do Rio Grande do Sul (1959-1963). Teias, Rio de Janeiro, ano 2, no 3 , jan/jun 2001, p. 1-12.

RAMOS, Marise Nogueira. O ensino médio ao longo do século XX: um projeto inacabado. In: STEPHANOU, Maria; BASTOS, Maria Helena Câmara. (Org.) História e memórias da educação no Brasil, vol. 3: século XIX. Petrópolis, RJ: Vozes, 2009, p. 229-243.

REVEL, Jacques. Maurice Halbwachs e os primeiros Annales. In: REVEL, Jacques. Proposições: ensaios de história e historiografia. Rio de Janeiro: EDUERJ, 2009. p. 47-72.

SANFELICE, José Luís. O Estado e política educacional do regime militar. In: SAVIANI, Dermeval (Org.). Estado e políticas educacionais na história da educação brasileira. Vitória: Edufes, 2011.

SAPIRANGA. Lei Municipal n. 5.636, de 25 de junho de 2015. Institui o Plano Municipal de Educação - PME, para período de 2015-2025, e dá outras providências. Sapiranga, RS, 25 de junho de 2015.

SCHNEIDER, Regina Portella. A instrução pública no Rio Grande do Sul. 1770-1889. Porto Alegre: Ed. Universidade/UFRGS/EST Edições, 1993.

SOUZA, José Edimar de. O uso de fontes orais na pesquisa em Lomba Grande/RS: aspectos das escolas isoladas (1940-1950). CONJECTURA: filosofia e educação, v. 21, n. 2, p. 441-459, 2016.

SOUZA, José Edimar de. As Escolas Isoladas: práticas e culturas escolares no meio rural de Lomba Grande - RS (1940 a 1952). 2015. 292 f. Tese (Doutorado em Educação) - Unisinos, São Leopoldo, RS, 2015.

SOUZA, Rosa Fátima de. História da organização do trabalho escolar e do currículo no Século XX: ensino primário e secundário no Brasil. São Paulo: Cortez, 2008.

SOUZA, Rosa Fátima de. Alicerces da pátria: história da escola primária no estado de São Paulo (1890-1976). Campinas, SP: Mercado das Letras, 2009.

TAMBARA, Elomar. Escolas formadoras de professores de séries iniciais no Rio Grande do Sul. Notas introdutórias. In: TAMBARA, Elomar; CORSETTI, Berenice (Org.). Instituições Formadoras de Professores no Rio Grande do Sul. Pelotas: UFPel, 2008. p. 13-39.

TAUNARI, Leonor Maria. História da formação de professores. Revista Brasileira de Educação, USP, maio/jun/jul/ago, 2000, n. 14, p. 61-88. 
VIDAL, Diana Gonçalves. Instituições escolares no Brasil: conceito e reconstrução histórica: Por uma ampliação da noção de documento escolar. In: NASCIMENTO, Maria Isabel Moura et al. (Org.). Instituições escolares no Brasil: conceito e reconstrução histórica. Campinas, SP: Autores Associados: HISTEDBR; Sorocaba, SP: UNISO; Ponta Grossa, PR: UEPG, 2007.

VIÑAO FRAGO, Antonio. Historia de la educación y historia cultural. Posibilidades, problemas, cuestiones. Revista Brasileira de Educação, [S.l.], n. o, p. 63-82, set-dez. 1995.

WERLE, Flávia. Escola Complementar como espaço de formação. Revista Veritas. PUC. Porto Alegre, v. 42, n. 2, junho 1997, p. 307- 316.

\section{Fontes}

\section{Arquivos}

Arquivo do Instituto de Educação Estadual Sapiranga - AIEES

Arquivo do Museu Municipal Adolfo Evaldo Lindenmeyer - AMMAEL

\section{Jornais}

O FERRABRAZ. Escola Normal Regional. 23 de fevereiro de 1963, capa.

FOLHA DE SAPIRANGA. Escola Normal Regional de Sapiranga - RGS. 16 de setembro de 1962. p. 6

FOLHA DE SAPIRANGA. Escola Normal também de $2^{\circ}$ Ciclo. 08 de novembro de 1962, p. 4.

FOLHA DE SAPIRANGA. Sapiranga reclama uma Escola Normal. 15 de abril de 1962, capa.

\section{Entrevista}

GERHARDT, Renilda Adi [75 anos]. [ago.2015]. Entrevistador: José Edimar de Souza, Campo Bom.

GERHARDT, Renilda Adi [77 anos]. [nov.2017]. Entrevistador: José Edimar de Souza, Campo Bom.

SANTOS, Érica Berg [85 anos]. [set. 2015]. Entrevista: José Edimar de Souza, Sapiranga. 